Swain, Spencer ORCID:

https://orcid.org/0000-0002-2191-0041 (2018) Grime music and dark leisure: exploring grime, morality and synoptic control. Annals of Leisure Research, 21 (4). pp. 480-492.

Downloaded from: http://ray.yorksj.ac.uk/id/eprint/2755/

The version presented here may differ from the published version or version of record. If you intend to cite from the work you are advised to consult the publisher's version: https://doi.org/10.1080/11745398.2018.1430597

Research at York St John (RaY) is an institutional repository. It supports the principles of open access by making the research outputs of the University available in digital form. Copyright of the items stored in RaY reside with the authors and/or other copyright owners. Users may access full text items free of charge, and may download a copy for private study or non-commercial research. For further reuse terms, see licence terms governing individual outputs. Institutional Repository Policy Statement

\title{
RaY
}

Research at the University of York St John

For more information please contact RaY at ray@yorksj.ac.uk 


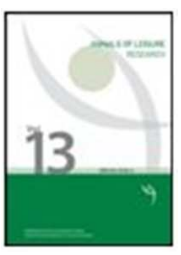

\section{Grime Music and Dark Leisure: Exploring Grime, Morality} and Synoptic Control

\begin{tabular}{|r|l|}
\hline Journal: & Annals of Leisure Research \\
\hline Manuscript ID & RANZ-2017-0004.R3 \\
\hline Manuscript Type: & Special Issue Article \\
\hline Keywords: & Grime Music, Dark Leisure, Morality \\
\hline \multicolumn{2}{|l}{} \\
\hline
\end{tabular}

\section{SCHOLARONE ${ }^{1 m}$ \\ Manuscripts}




\section{Grime Music and Dark Leisure: Exploring Grime, Morality and Synoptic Control}

Abstract: Grime music represents a much-maligned leisure culture within contemporary British society, a point exposed by calls for the genre to be banned. This paper puts forward a perspective that challenges such a rigid interpretation by revealing how certain forms of Grime can be read as moral, exposing the manner in which such music encourages listeners into education, diverting them from the perils of gang violence and drugs. However, the paper narrates how this more 'respectable' form of Grime finds itself confined to the annals of dark leisure, through examining the contours of power that run through contemporary society, explored through the auspices of synoptic control. Here, the paper calls for a more contextual analysis of Grime that focusses on defining the moral messages that individual artists express rather than relying on the essentialist principle of categorising the whole genre in a negative manner. 
The relationship between music and dark leisure represents a fascinating topic for leisure scholars to explore; particularly when evaluating the different paths such research can take in developing our understanding of morality. Nevertheless, in spite of the potential this avenue of exploration holds in forging a greater insight into perceptions of deviance, there has been a reluctance to engage with this area, leading to a situation where historically music based research has been marginalised within leisure studies. In recent years, however, this has begun to change. This is due in part to the gradual emergence of more progressive leisure scholars, who have started looking at the relationship between music and people's leisure lives (see, Lashua and Fox, 2006; Lashua and Kelly, 2008; Spracklen, 2014; Riches, Lashua, and Spracklen, 2014). Such insight has advanced our understanding of the role that musical genres, such as Goth and Hip-Hop, play in day to day life, connecting topics as diverse as identity, resistance, and consumption to the lexicon of musical leisure cultures. It is important to note here, that not only have these works started to connect leisure studies to the cultural world of music, they have also been integral to the writing of this paper, by helping to provide the intellectual curiosity to explore Grime music and its complicated relationship with dark leisure.

It is not lost on the author that the genre of Grime music may not be instantly recognisable to many readers, a testament perhaps to the marginalised position of Grime within popular music discourses and leisure literature. To this end, the paper starts by providing an in-depth insight into Grime, charting its origins in East London, to its meteoric rise in becoming one of the most distinct urban sounds in Britain and a staple of a vibrant inner-city music scene. Here, it is explained how such accolades have catapulted Grime onto the margin of public consciousness, while at the same time encapsulating the genre as a prominent leisure culture for many in Britain's marginalised communities. However, to divulge the full story surrounding Grime, the reader will also learn how this increase in recognition has fuelled condemnation, with many in the cultural mainstream expressing deep-seated reservations about the genre's perceived role in glorifying a violent form of 'street culture'. This situation has led to an uneasy and damaging association between Grime and transgressive behaviour, an image that has gone on to etch itself firmly into the public psyche. The impact of such denigration is explored in the paper and is held up as a reason for stopping many artists receiving the widespread acclaim they desire, as well as record labels refusing to sign acts, and promoters being wary of running club nights (Baron, 2013).

The paper questions this essentialist reading by articulating how the Grime scene is split irreparably, between those artists who adopt a 'street' or 'badman' style built around illicit behaviour and a 'respectable' trope that encourages listeners to 'better themselves' and think about others in their community. This distinction represents a moral paradox, and in so doing highlights 
the call set out by progressive leisure theorists (see, Blackshaw and Crabbe, 2004; Blackshaw, 2010; Rojek, 1999; Spracklen, 2013) to develop a sophisticated understanding of dark leisure that can account for this diverse array of musical styles. The use of such an approach is shaped around providing a contextual analysis of morality, which articulates the Grime scene in a contingent manner, while simultaneously exposing the power mechanisms that influence peoples perceptions of deviance in contemporary society.

$\underline{\text { Grime Music }}$

Grime music constitutes a syncretic musical culture born out of different points of what Paul Gilroy (1993) aptly terms the 'Black Atlantic', fusing elements of North American, African, Caribbean, and British culture. Historically, Grime emerged out of musical styles as diverse as 'House', a form of electronic dance music that was popular in North America in the late 1980s, and 'Acid House', a distinct form of British rave culture (Thornton, 1995). It was from these foundations that the musical genre began to take root, first finding expression in 'Garage' and 'Jungle', sounds that became synonymous with the inner city estates of London during the mid-1990s. As time went on Grime gradually began to emerge as its very own distinct style, infusing a variety of musical sources to generate a separate cultural sound, built around a heavy bass production and street aesthetic. This style drew extensively on a synthesis between the Jamaican tradition of 'toasting' (singing to a rhythm), and American 'rapping', both of which embraced the central role of MC (Master of Ceremonies) vocalists (Baron, 2013). To many, the lyrical content of Grime makes the genre distinct from other urban sounds, providing artists and listeners with a vehicle to express their innermost thoughts and insights into life in Britain's multicultural inner-city milieu (llan, 2012).

It was during the early 2000s that Grime music started to forge a distinct musical sound, formally disassociating itself from 'Jungle' and 'Garage'. Emanating out of London's very own Orient, the East End district of Bowe, a variety of artists, led by Wiley the self-confessed pioneer of Grime, started to experiment with a faster, stripped-down sound that placed a greater emphasis on lyrical content (Dedman, 2011). The importance given to lyrics enabled such music to occupy a prominent position within the estates of Britains inner cities, acting as an escape valve for many young people to express their innermost thoughts and struggles. At their core, many of these insights focused on cycles of poverty, the spectre of racism, and criticisms of a political system that many perceived as being out of touch with the day to day reality of the inner-city (Hancox, 2009). Interestingly, and in many ways unsurprisingly, this distinct sound and the lyrical content associated with it allowed Grime to become uniquely related to the struggles of London's, and increasingly wider Britain's, disenfranchised inner-city communities (Wheatley, 2010). 
Artists tend to communicate their experiences of living in violent environments, bereft of opportunities, yet located near sites of wealth and prosperity, the consequences of which have led to Grime music becoming linked to the inequalities of poverty, racism and social exclusion (Ilan, 2012). Such areas foster a 'street' culture that has manifested itself as an interpretive logic, that uses the medium of music to forge a site of cultural expression. However, it is important to recognise that such expression is viciously contested, something that causes Grime to be a complex genre to decipher. Here, lyrics are used in a rather contradictory manner, exuding both a positive sense of communalism as well as a negative undertone that glorifies violent metaphors and disingenuous lifestyles based on drugs, illicit sexual behaviour and the denigration of women (Sandberg, 2008). Unfortunately, for many in the associated press, cultural industries, and Government, Grime music continues to be seen as a cynical genre that glorifies theft, drug-taking, stabbings, and shootings. These stereotypes link into a wider understanding that projects the genre as being built around robust fundamentals of braggadocio, encompassing a 'badman' snarl and tough-talking that fit into a vernacular of demonstrating 'street capital' (Dedman, 2011). This perspective is unpacked in detail by Ilan $(2012$, p.46):

The response of institutional authorities in the UK has arguably been to interpret Grime music as symbolic of danger and transgression, further marginalising the music and impacting on the means by which it might be commercialised.

It goes without saying that such negativity has placed Grime in a precarious position, due in part to the way institutional discourses have caused members of the public to view such music as deviant and uncivilised, particularly in comparison to more acceptable tropes such as pop and classical music. Here, the paper turns to focus on how such deterministic thinking has affected the public's understanding of Grime's relationship with morality.

Grime Music and Dark Leisure: Exploring 'The Street Snarl'

Grime music is often perceived to represent a vehicle of cultural expression that promotes messages of aggression and uncivilised behaviour. The rationality behind this image centres on Grimes close association with negative understandings of 'street culture', built around a reading of a 'badman' masculinity that exudes a narrative of dominance. This masculinity communicates hostile aggression towards potential rivals, in the form of other MC's and institutional figures such as the police (Illan, 2012). At their heart, the use of such lyrical content aims to demean others by 'murking' (beating) them through highly charged verbal messages, communicated through media content or via face to face confrontation. The purpose of such derogatory lyrics centre on exposing the particular artist's notoriety, serving to elevate the MC's 'street cred' (reputation) on the 'road' (local area/scene). An 
The use of such lyrics serves to expose the animosity and braggadocio associated with Grime music, evidenced by terminologies that refer to 'slewing' (beating) and making 'dough' (money). These messages help develop an emotive connection that further consolidates Grimes negative relationship with crime and violence, while also playing a significant role in enhancing the wider public's negative perception of inner city areas and the communities that live within them. This point is evidenced in the lyrics of the South London Grime artist Giggs (2010) and his freestyle 'Don't Go There'. Here, Giggs conveys the image of inner city communities as being anti-police and deviant, entrenching an adverse image into the public consciousness:

You don't know where my people coming from cause you don't go there. We just tryna make dough [money] here, Feds [police] on our case, so we moving mad low here.

The feelings of marginalisation, transgression, and criminality portrayed by Grime have fuelled perceptions of inner-city neighbourhoods as feral 'no-go areas', constructing dominant images of such localities as bastions of transgressive behaviour. These feelings, communicated through evocative lyrics about 'the ghetto' or 'hood', enhance this sense of meaning, value and identity. The downside of such lyrics help to fuel negative perceptions of the genre, leading to calls for Grime to be banned from the airwaves (Baron, 2013). Of particular interest here, is the argument put forward by many in society, who articulate how Grime has only itself to blame for its precarious position on the British music scene, due in part to the propensity of its artists to promote an undesirable image to the outside world. This situation has led to a symbolic identification between Grime and inner-city 
communities, a point described by Dedman (2011, p.519) as constituting a mentality whereby the genre has become linked to impoverished, ethnically diverse enclaves of inner cities and strongly perceived as: "their music."

Ilan (2012) explains how such negativity has led to record labels being reluctant to sign high profile Grime artists. Most notably MC's such as Skepta, JME, and Jammer, have found themselves falling victim to this cautious approach which continues to interpret Grime as problematic, and constituting an image that many recording companies feel might tarnish their reputation amongst mainstream listeners. This rejection has only invigorated Grime's association with the marginalised and dispossessed, a point highlighted by many artists who promote their authenticity by communicating how they are not signed with mainstream record labels, something which in turn validates a message designed to express how they are keeping their content 'real'. This claim does have a degree of validity in regards to the way certain artists use their music to highlight major social problems such as poverty, police brutality, and substance addiction. Others, manipulate this call for authenticity by appealing to the problematic performance of negative 'street tropes' by glorifying guns, sex and the demeaning of potential enemies. It is the propensity of such artists to appeal to this somewhat distorted vision of Grime that generates a severe public backlash from social institutions and community organisations.

The negativity surrounding Grime and its close association with 'street culture' has led to ramifications in the realm of leisure, with many nightclub promoters being wary of running events themed around the genre, due in part to the propensity for violence to occur. As Baron (2013) states, many Grime events court the increased possibility of violence occurring, usually in the form of knife attacks and shootings. A notorious example of this was the killing of innocent bystanders Charlene Ellis and Leticia Shakespeare in Birmingham during a New Year's Eve celebration in 2003. In this instance, two rival gangs, from the Aston and Handsworth areas of the city, clashed outside a nightclub venue when it was communicated to one of the gangs that an MC was 'spitting' (rapping) lyrics that made fun of a fatal stabbing that had occurred just days earlier. On hearing news of this, three members of the rival gang decided to drive by and spray the venue with a Mach 10 machine gun, killing the two innocent young women and injuring several bystanders in the process (Wilson, 2013). The memory of this tragic event and the spike of incidents involving rival Grime crews at live music venues has caused nightclub promoters to be wary of such incidents happening at events they organise. Such animosity has been compounded yet further by the clumsy and often discriminatory tactics of police forces, who often employ heavy-handed tactics while policing Grime venues, leading to increases in complaints and strained relationships with inner-city communities (Dedman, 2011). 
Grime Music and Conventional Perspectives of Dark Leisure

This negative perception of Grime has given rise to the belief that such music constitutes a form of dark leisure (Rojek, 1999). Due in part to the way broader public perceptions of the genre go against the social and cultural orthodoxies of what free time is supposed to entail (Stone and Sharpley, 2008). The consequences of this have led many politicians to call for Grime to be banned from the airwaves, restricting artists from using the medium to communicate their beliefs and experiences to vulnerable youngsters who might be easily impressionable and take up such disingenuous lifestyles. At the centre of this discourse was the MP David Cameron, who in 2005 during his time as leader of the opposition, expressed his concerns about the social messages Grime was conveying to sections of society. The focus of Cameron's criticism centred on the widespread belief that Grime music embodied the wave of anti-social behaviour sweeping British society at the time. In particular, his assertion that such music was 'sick' and representative of a medium that spread anti-social messages, led many in the political elite to call for Grime artists and DJs to be banned from disseminating their music (Kubrin, 2005).

To understand the ideology behind such thinking, we have to go back over a century to one of the founding fathers of sociology, Emile Durkheim (1972). Durkheim developed his philosophical position on ethics by reinforcing the need for a secure foundation through which understandings of moral behaviour could be classified. The central principle behind such thinking was that ethics represented a social fact, reinforced through the reality of society and symbolised by a 'religion of humanity'.

To regulate our relations with men, it is not necessary to resort to any other means than those, which we use to govern our relations with things; thought, methodically employed, is sufficient in both cases. What reconciles science and ethics is the science of ethics, for at the same time that it teaches us to respect moral reality; it gives us the means to improve it. (Durkheim, 1972, p.121)

This approach affirms Durkheim's belief that a rule-guided moral code should define obligations and duties according to a categorical imperative. The implications of such a method reveal themselves in the idea that moral behaviour should be influenced by ethical legislation that negatively sanctions thoughts and actions that are deemed deviant by social institutions. This perspective exposes Durkheim's view that society should take on the role of being the 'guardian of the soul', playing a prominent role in sanctioning activities that are perceived to be deviant. At the core of this argument is the belief that a breakdown in society would lead to a crisis in individual morality, allowing the desires of the population to become unhinged without the safety harness of the state 
to suppress them. This line of reasoning can be seen in calls for a ban on the dissemination of Grime music, exposing how social and political elites seek a moral superiority over their populations, particularly in regards to defining issues relating to ethical behaviour.

However, while some have been quick to use Grime as a scapegoat for the burgeoning social problems affecting Britains' inner cities, these views only tell a partial story of the role the genre plays in the leisure lives of many listeners and fans. The next section provides a different perspective, putting forward a more nuanced and positive view of Grime that unpacks the 'respectable street tropes' that run through the genre, and encourage disadvantaged youth to participate in society and better themselves. At its core, this perspective attempts to contextualise how Grime music is a complex genre that must be explored from a variety of angles to develop a deeper understanding of the moral undertones that guide different artists.

\section{Exploring 'Respectable Street Tropes'}

Existing in direct antithesis to the negative 'badman' aesthetic sit the palatable images communicated by more 'respectable' Grime musicians. At their core, the lyrical content and social images they communicate help emphasise the importance of remaining law-abiding and engaging with mainstream society (Anderson, 1999). The central theme running through such music encourages listeners to remain in education and participate in legitimate forms of entrepreneurialism to better themselves and their communities. It, therefore, comes as no surprise, that such a medium resonates with the values of aspiration and respectability, helping to nullify the abrasive images communicated through the 'badman' aesthetic, by instead championing a positive message that resonates with inner-city youth. Illan (2012, p.47) explains this in the following way:

Grime artists, given their young age, are often still in education and often show pride in their achievements. Chipmunk [Grime artist], appeared on BBC 1 Xtra radio to discuss his A Level results. Tinchy Stryder, an artist who has achieved number one hits in the British charts, has spoken in positive and encouraging terms about his time at university. JME, a distinguished underground Grime MC, has discussed his educational ambitions in detail, lyrically.

While this image of Grime encompasses a less violent message than the more recognisable 'badman' aesthetic discussed previously, there is still a propensity for artists to show off consumer wealth. However, it is important to distinguish the complex undertones behind this message, a point that can be unpacked through analysing the entrepreneurial image communicated to audiences through particular lyrics. A prime example of this is the message conveyed by Wiley (2007), through the mantra of "I wear my own garms (clothes)", which represented the key message behind his hit 
single 'No Qualms'. At its core, these lyrics reject the negative influence of conspicuous consumption and instead emphasise the importance of entrepreneurialism. The use of such a sophisticated approach to consumerism represents a break with conventional understandings of urban music that have historically been shaped by perceptions of American rap culture (Haywood, 2004; Rose, 1994). Here, the spectre of conspicuous consumption promoted by American artists is seen as being connected to their exclusion from mainstream society, while more 'respectable' Grime tropes recognise how the presentation of consumer goods should not be separate from the means required to purchase such products. The underlying rhetoric behind this message has helped develop a mentality that connects the procurement of consumables with hard work, rather than a singular desire to show off affluence and status (Baron, 2013). As a consequence, one of the major positives of the 'respectable' Grime trope is that it dissuades listeners from using violence or other illicit means to procure consumables and instead introduces them to more legitimate approaches of achieving their aspirations. This point is highlighted by JME (2007) in his popular single 'Serious':

Everybody thinks to $\mathrm{MC}$ tough, Your lyrics must be about negative stuff, Go raving no-ones skanking [dancing], Turn round I bet you someones shanking [stabbing], Just cause we come from the gutter, And we know about scraping the bottom of the butter, Don't mean we have to be sinners, Major labels don't want killers, Think, who's gunna sign a guy with a shank [knife], Or a guy with a 9 mil [gun], All you're gunna get is a 3 figure deal, $M C$ at a rave and get a bil (£100)l, But that bill ain't gunna last, It will go fast and it mite be the last, Shorts for a while so you won't have no dough [money] for a while.

The use of such lyrics highlights an alternative narrative that encourages audiences to make rational choices in their lives that will reduce their marginality. It, therefore, comes as no surprise that more 'respectable' forms of Grime music have been used as a vehicle to spread a wide variety of social inclusion messages, helping to influence issues as diverse as education, violence, and gun/knife crime (Dedman, 2011). The propensity of such artists to think about the moral welfare of others helps their music create a different image for disenfranchised communities to aspire to, moving away from traditional readings that equate Grime with criminality and negativity. Once again, the example set by JME (2008) exposes how artists use their lyrics to encourage marginalised youth into education:

I stayed in school got my degree, even if I get a 2:2, I've done it, time waste for no-one. This year I was 2:2, my dad wants me to do a masters, and my mum wants me to too. (JME, 2008, 'Famous')

The message of encouraging youth into education is matched by other initiatives aimed at getting young people to move away from the allure of being involved in gun and/or knife crime. Here, the involvement of one of Londons' largest Grime 'Crews' (groups) Roll-Deep in the 'Stop the Guns' 
campaign (2006) championed by the Metropolitan police and the then Mayor of London Ken Livingston provides a pertinent example of the groundwork being undertaken by certain artists. Similarly, other influential Grime artists have challenged pervasive attitudes towards violence in their music (Illan, 2012). A prominent example of this is the North London recording artist Bashy, who linked up with the famed television producer Noel Clarke to perform a cover for the hit film 'Adulthood' (2008). At its core, 'Adulthood' sought to dissuade young adults from engaging in violent acts against one another, showing the graphic consequences of how personal feuds can result in further poverty for protagonists, their families, and wider communities:

And I move like pirate, raves, mixtape, album. Done with the clashing I've seen the outcome. Nuff badman on road been around them. Nuff MC's on the scene I could out them. But allow [forget] them. Cause it's not about them. The roads are nuts like almonds. I'm a musician and I use my position. To influence thousands. Look, I said I'm not on a hype cause. I'm far from a kidult now, I'm much wiser. Blud I'm older I'm grown up. So now I gotta act like a grown up. I used to be wild, I was acting raggo. On the defensive acting paro (paranoid). But now I'm on the straight and narrow. Cuzzy I've gone from a kid to an adult. (Bashy, 2008, Kidulthood to Adulthood)

Here, Bashy and other similar minded artists, who collectively represent a more 'respectable' style of Grime, use their lyrics to communicate how 'real' men and women are not prepared to risk the wellbeing of others through partaking in meaningless personal feuds. Moreover, this mentality represents a wider shift away from seeing crime and personal feuds as being a legitimate part of Grime music, due to the manner in which such music encourages listeners to think about the welfare of others in their communities. In so doing, this style directly opposes the 'badman' image of Grime that has saturated the public consciousness, signalling a shift in the cultural dynamics of the genre by developing a distinct message of inclusion and communal welfare.

\section{Grime, Moral Responsibility and Situational Perspectives on Dark Leisure}

This reading of Grime music opens the discussion up to a more nuanced interpretation of morality and dark leisure. Here the work of Zygmunt Bauman (2000) and his writings on 'liquid modernity' are integral to explaining how universally constructed understandings of ethical behaviour, communicated by ethicists such as Durkheim need to be challenged through a more nuanced perspective crafted around the notion of 'moral responsibility'. To be able to explain the environmental conditions under which such a reinterpretation can take place, it is important to articulate the central tenants of 'liquid modern' thought. Here, Bauman uses the metaphor of liquidity to interpret the transformations impacting society that have seen the dissolution of the 'solid modern' world structured around the guiding principle of state planning and regulation, to a 
'liquid modern' one that exudes uncertainty. This transformation, brought on by the rampant effects of globalisation and turbo-capitalism instigated by the neo-liberal policies adopted by many national governments, has created an environment where social forms can no longer, and are no longer expected to, hold their shape for long. This metamorphic transition has resulted in a shift in the responsibilities for personal welfare, which have now moved from the realm of social institutions onto the shoulders of individuals. As Bauman (2000, p.3-4) explains, in contemporary society, people are now expected to be "free choosers and bear the full consequences of their choices."

However, Bauman (1993) contends that a potential benefit of this social transformation exposes itself in the growing shift towards independent 'self-examination' and the potential this can bring in dismantling instrumental rationalities that have governed society and sources of moral reasoning since the time of 'The Enlightenment'. The central tenant of this message does not call for the concept of morality to be discarded. Instead, Bauman (1995) argues quite the opposite, calling for its restoration through the creation of a new moral principle, one which can provide individuals living in 'liquid modern' times with a new way of guiding their moral commitments. A prominent figure, used by Bauman to help in this quest for a more contingent and situational understanding of morality, is the Lithuanian philosopher Emmanuel Levinas (1969). The synthesis of these two minds, in turn, has led to the creation of a nimble approach to the theorisation of morality that most "orthodox approaches leave invisible" (Bauman, 1989, p.182). At the centre of Levinas's (1969) work is his disdain for rigid ontological assumptions about ethics that propose distinct institutionally guided interpretations of morally conducive behaviour. To this end, he sets out a position that focusses on the moral welfare of the other, creating a thought process where rather than treating the other as a mere object of perception or as a process of thought, they are instead conceived as a fundamental concern.

This perspective challenges the ontological structure of being-with, which operates on the assumption of sameness and symmetry, by instead replacing it with the ethical perspective of beingfor, accounting for asymmetry and difference (Levinas, 1969). The notion of being-for-the-other becomes situated as a very particular encounter based on the idea of precariousness, a belief that champions the idea of one human caring for another without demanding anything in return. This perspective elucidates how 'moral responsibility' for the other precedes "societal intervention and manipulation" (Bauman, 1998 p.145), helping to clarify both Bauman's (1995) and Levinas's (1969) assertion that such care is the underlying theme guiding moral behaviour. 
To put it in a nutshell, we may say that moral responsibility tends to grow in such situations in which contractual obligations tend to shrink, and vice versa. Moral responsibility is greater the weaker and more helpless the Other (Bauman, 1998, p.19)

This nuanced perspective allows the paper to explore how Grime's relationship with dark leisure can be rearticulated using this more contingent and situational approach. At the core of this view is the need for a method that looks deeper into the messages conveyed by Grime artists, in particular, the manner in which they show a level of 'moral responsibility' towards those in their community and beyond (Bauman, 1993; 1995; 1998). This sophisticated perspective on morality can be unpacked further through reminding the reader of the way 'respectable' Grime tropes have encouraged youngsters in deprived inner-city areas to partake in education, to refrain from involving themselves in gang culture, and to relent from needless violent behaviour against others. Add to this, the prominent role that Grime artists like JME and Stormzy have played in helping to increase voter turn out at the 2017 General Election in the UK, by encouraging disadvantaged youths to exercise their democratic rights and discuss political issues during their leisure (Hancox, 2017). In addition, there is the way Akala, a prominent North London artist, has used media appearances on current affairs programmes like Newsnight to expose the poor treatment of Grenfell Tower victims by both local and central government. All of these highlight how Grime acts as a powerful medium in challenging the gross inequalities that characterise British society (Davies, 2017). These examples show how 'respectable' Grime tropes exude a strong sense of 'moral responsibility' to others, particularly the disadvantaged, by standing up to social and political elites and exposing the growing levels of inequality that haunt twenty-first century Britain.

\section{Grime Music and Synopticism: New Methods of Sanctioning Dark Leisure}

However, despite this more nuanced reading into the relationship between Grime and dark leisure, it is essential to return to the beginning of this discussion, by articulating why the genre is still perceived to be deviant by the majority of people within society. Here, it is explained how this negative perception is connected to a new method of power and control unique to the 'liquid modern' epoch. To be able to unpack this shift, the discussion must start with the work of the French philosopher Michel Foucault (1977) and his concept of the panopticon. Foucault described how the panopticon - the 'all seeing eye' of a large prison like structure designed to observe inmates represented the method through which citizens were ordered during the epoch of modernity. This mechanism achieved control through disciplining, marginalising, and subordinating behaviour that social and political institutions legislated as being immoral. It was through the implementation of 
this 'normalising gaze' that the type of ethical legislation proposed by social thinkers like Durkheim (1972) was able to flourish.

In recent years, it has been argued that the auspices of panoptic control have been replaced by what Thomas Mathiesen (1997) aptly identifies as the synpoticon. The work of Mathiesen helps the discussion explain how the repressive apparatus of the panopticon has been supplanted by a method of control that involves watching. In other words, the few no longer watch the many (panopticon); instead the many now watch the few (synopticon). The power of this method of control manifests itself through the development of new technologies and social media platforms, that allow the consumer masses to watch the few (celebrities and other VIP's). Something which Bauman (2000, p.30) explains in the following way:

It is now your task to watch the swelling ranks of Big Brothers and Big Sisters, and watch them closely and avidly, in the hope of finding something useful for yourself: an example to imitate or a word of advice about how to cope with your problems, which, like their problems, need to be coped with individually and can be coped with only individually.

The significance of synoptic control, for this discussion, is that unlike the repressive apparatus of the panopticon, there is no longer any form of coercion needed to hold individuals back. It is now individuals themselves who seek out models and courses of action to follow by looking at the examples set out for them by different role models, the 'Big Brothers' and 'Big Sisters' of contemporary society, those in the public gaze who provide the examples that others follow. As Blackshaw and Crabbe (2004) explain, this has led to a situation where deviance is policed from afar, through the concept of 'self-government'. Here, certain musical leisure cultures become stigmatised as being irrational or uncivilised by the 'expert systems' that provide the information through which the consumer masses make their ethical judgements.

The marginalisation of Grime music represents an example of synoptic power in operation, exposing how the genre is portrayed in mainstream media as being associated exclusively with the 'badman' street aesthetic that exudes criminality, sexual promiscuity, and violence. This image, in turn, causes Grime to receive little mainstream recognition from consumer orientated 'experts' and 'expert systems' (Giddens, 1991), leaving artists bereft of commercialised platforms to promote their music and the message it conveys. It is this inability to contextualise Grime music through a more sophisticated perspective that has caused 'respectable' Grime cultures to remain confined to the abstract image of crime and violence, associated with parts of the inner city often distinguished as the bastions of transgressive behaviour. To put this another way, one can argue that Grime music has become restricted to the confines of dark leisure, due to the genre's association with parts of 
society that many in the consumer classes view as being beyond the pale of rational thought (Bauman, 1998). As a result, such negative images stop individuals looking deeper into and challenging their assumptions about Grime representing a form of dark leisure. This is due in part to their fear of being associated with a musical leisure culture that many in the social and political elite perceive as being the symbol of 'Broken Britain' and the epitome of transgressive behaviour. Subsequently, the use of a more contextualised perspective of analysing Grime's relationship with deviance through assessing the social messages and lyrics communicated by artists using the concept of 'moral responsibility' is discarded. In its place comes a pervasive attitude that causes many to ignore its moral undertones, fuelling the stigmatisation of such music without ever looking deeper into the distinct fault lines that run through it.

\section{Conclusion}

To conclude, the central theme of this discussion articulates how Grime music represents a unique musical leisure culture that has an ambivalent relationship with dark leisure; a perception built around two polemic arguments. The first, held by the majority in mainstream society views such music as a bastion of trangressive behaviour, representing a symbol of 'Broken Britain'. While the second goes far deeper into the genre by examining the moral undertones that influence the lyrics and social messages of certain artists, exposing how they exude a sense of 'moral responsibility' for others. This paper has examined how such music continues to be understood disingenuously by the majority of people in society, due to the auspices of synoptic control (Bauman, 2000; Blackshaw and Crabbe, 2004), a theory which exposes how public perceptions of moral leisure are still open to external manipulation. Here the paper examines how this new 'inclusionary reality' of what constitutes moral leisure is built around the accepted wisdom of consumerism and the tactics of seduction and repression. The consequences of this are articulated through the way such music remains deviant in the eyes of many due to the genre's lack of legitimation by style 'experts', those who help guide the moral reasoning of the population. As a consequence, many in the consumer masses fail to distinguish between the different types of artists that make up the Grime scene and passively stigmatise their messages as being abusive and braggadocios, thus avoiding any association with the genre for fear of being read in the same way by others.

This inability to distinguish between different types of Grime music highlights how the moral perceptions of populations within post-industrial countries have shifted from being institutionally sanctioned to consumer-driven, guided by the influence of aesthetics and performativity. At its core, such a shift exposes how this new 'weapon of ethical legitimation' represents a potent threat in stifling the ability of individuals to make moral decisions by themselves, reducing the propensity of 
many to define dark leisure through a situational and positional lens based around 'moral responsibility'. The consequences of this leave Grime music and the many positive messages it conveys firmly on the margins and invisible to many, a point that further exposes the problems facing such musical leisure cultures in a postmodern world.

Bibliography

Anderson, E. (1999). Code of the street: Decency, violence, and the moral life of the inner city. New York: Norton \& Co.

Baron, L. (2013). The sound of the street corner society: Uk grime music as ethnography. European Journal of Cultural Studies, 16(5), 531.

Bauman, Z. (1989). Modernity and the holocaust. Itacha: Cornell University Press.

Bauman, Z. (1993). Postmodern ethics. Cambridge: Blackwell.

Bauman, Z. (1995). Life in fragments. essays in postmodern morality. Cambridge: Blackwell.

Bauman, Z. (1998). What prospects of morality in times of uncertainty? Theory, Culture \& Society, 15(1), 11.

Bauman, Z. (2000). Liquid modernity. Cambridge: Polity.

Bauman, Z. (2001). The individualized society. Cambridge: Polity.

Bauman, Z., \& Tester, K. (2001). Conversations with zygmunt bauman. Cambridge: Polity.

Blackshaw, T. (2010). Leisure. London: Routledge.

Blackshaw, T., \& Crabbe, T. (2004). New perspectives on sport and 'deviance': Consumption, peformativity and social control. London: Routledge.

Butler, J. (1990). Gender trouble: Feminism and the subversion of identity. New York: Routledge.

Davies, H. (2017). 'We respect them': How musicians kept the UK's attention on Grenfell. Guardian.

Dedman, T. (2011). Agency in UK hip hop and grime youth subcultures - peripherals and purists. Journal of Youth Studies, 14(5), 507.

Durkheim, E. (1972). Emile Durkheim: Selected writings. Cambridge: Cambridge University Press. Foucault, M. (1977). Discipline and Punish: The birth of the prison. London: Pantheon Books. 
Giddens, A. (1991). Modernity and self-identity. self and society in the late modern age. Cambridge: Polity.

Gilroy, P. (1993). The black atlantic: Modernity and double consciousness. London: Verso.

Hancox, D. (2009, 14 February). The triumph of grime. Guardian.

Hancox, D. (2017, 5 June). Why Grime might save the Labour Party. Guardian.

Hayward, K. (2004). City limits: Crime, consumer culture and the urban experience. London: Glasshouse.

Ilan, J. (2012). 'The industry's the new road': Crime, commodification and street cultural tropes in UK urban music. Crime Media Culture, 8(1), 39.

Kubrin, C. (2005). Gangstas, thugs and hustlas: Identity and the code of the street in rap music. Social Problems, 52(3), 360.

Lashua, B. and Fox, K. (2006). Rec needs a new rhythm cuz rap. is where we're livin'. Leisure Sciences, 28(3), 267.

Lashua, B. D., \& Kelly, J. R. (2008). Rhythms in the concrete: Re-imagining the relationship between space, 'race' , and mediated urban youth cultures. Leisure/Loisir, 29(2), 461.

Levinas, E. (1969). Totality and infinity. Pittsburg: Duquesne University Press.

Mathiesen, T. (1997). The viewer society: Michel Foucault's ‘Panopticon' revisited. Theoretical Criminology, 1(2), 215.

Riches, G., Lashua, B., \& and Spracklen, K. (2014). Female, mosher, transgressor: A 'moshography' of transgressive practices within the leeds extreme metal scene. laspm@journal, 4(1), 87.

Rojek, C. (1999) Abnormal leisure: Invasive, mephitic and wild forms. Loisir Et Societe/Society and Leisure, 20(2), 383.

Rose, T. (1994). Black noise: Rap music and black culture in contemporary america. Hanover: University Press of New England.

Sandberg, S. (2008). Black drug dealers in a white welfare state: Cannabis dealing and street capital. British Journal of Crimonology, 48(5), 604.

Spracklen, K. (2013). Leisure, Sports \& Society. Basingstoke: Palgrave. 
Spracklen, K. (2014). There is (almost) no alternative: The slow 'heat death' of music subcultures and the instrumentalization of contemporary leisure. Annals of Leisure Research, 17(3), 252.

Stone, P., \& Sharpley, R. (2008). Consuming dark-tourism a thanatological perspective. Annals of Tourism Research, 35(2), 574.

Tester, K. (2004). The social thought of Zygmunt Bauman. Basingstoke: Palgrave.

Thornton, S. (1995). Club cultures: Music, media and subcultural capital. Cambridge: Polity.

Wheatley, S. (2010). Don't call me urban: The time of grime. Newcastle: Northumbria Press.

Wilson, P. (2013). Letisha shakespeare and charlene ellis shootings: 10 years on. Retrieved from http://www.bbc.co.uk/news/uk-england-birmingham-20861868 